\title{
IMPACTO DE LA “TELEVISIÓN BASURA” EN LA MENTE Y LA CONDUCTA DE NIÑOS Y ADOLESCENTES
}

\section{Impact of "trash TV" on children and adolescents' mind and behavior}

\author{
Manuel Arboccó de los Heros* \\ Jorge O'Brien Arboccó **
}

\begin{abstract}
Resumen
En el siguiente trabajo se reflexiona sobre el impacto negativo que genera el mal empleo de la televisión en nuestro medio y en otros países. Revisaremos su uso y abuso y el fenómeno de la "televisión basura" como uno de los factores que propician una serie de deficiencias en la mente y la conducta de las personas, en especial los niños y adolescentes. Se recordarán una serie de importantes investigaciones y conclusiones alcanzadas por especialistas en el área y plantearemos una serie de recomendaciones para intentar detener el daño ya iniciado.
\end{abstract}

Palabras clave: Educación, televisión basura, homo videns, embrutecimiento, manipulación

\begin{abstract}
In the next job it reflects on the negative impact that generates the bad use of television in our environment and in other countries of the world. We will review its use and abuse, and the phenomenon of the "trash TV" as one of the factors favoring a number of shortcomings in the mind and the conduct of persons, in particular children and adolescents. A series of important research and conclusions reached by specialists in the area will be remembered and we raise a series of recommendations to try to stop damage already under way.
\end{abstract}

Keywords: Education, TV trash, homo videns, brainwashing, manipulation

* Psicólogo. Profesor Universitario. Egresado de la Maestría en Psicología por la Universidad Nacional Mayor de San Marcos. manoloarbocco@gmail.com

** Docente. Psicólogo Social. Docente de la Asociación Educativa Pitágoras. jorgebrett@yahoo.com 


\section{INTRODUCCIÓN}

"El hombre actual se caracteriza por su pasividad y se identifica con los valores del mercado porque el hombre se ha transformado a sí mismo en un bien de consumo"

-Erich Fromm

(Psicoanalista y filósofo de origen judío alemán)

\author{
"Vivimos en la cultura de la incultura" \\ -Giovanni Sartori \\ (Sociólogo y filósofo italiano)
}

Hoy se observa a muchos niños y jóvenes que parecen haber cumplido las profecías de grandes teóricos como el humanista Erich Fromm o el escritor argentino Ernesto Sábato quienes ya se ocupaban de la pérdida de la espiritualidad y la condición humana de las nuevas generaciones absorbidas por un mundo de plásticos y tecnologías así como ideologías de medio pelo. En nuestra labor como psicólogos y docentes hemos podido ver como en los últimos años los niños y los adolescentes están hoy por hoy mucho más expuestos a una parafernalia tecnológica cada una más demandante y cambiante que la otra. Queremos tocar esta vez el tema de la televisión y su impacto en la psique humana, sobre todo la infantil por considerarlo un tema importante y de repercusión en la mente juvenil y en temas esenciales como la escolaridad, el juicio lógico, el manejo de la palabra, la convivencia armoniosa, la inteligencia y las actitudes positivas y sanas.

Sabemos que existe esa llamada "televisión basura" que no es más que un conjunto de programas de televisión cuyos contenidos son muy pobres tanto en la propuesta cognitiva como en la socio-afectiva que nos brindan, por decir dos aspectos centrales que forman la riqueza psicológica de cualquier ser humano. Por eso a continuación presentamos, a manera de síntesis, una serie de informes y artículos de investigación que han venido estudiando los peligros de alimentar a los más pequeños -y más vulnerables- con horas y horas de una programación embrutecedora, ordinaria y alienante. De este tipo de televisión y la psicología es de lo que trata el siguiente artículo.

\section{DEFINIENDO EL TÉRMINO TELEVISIÓN BASURA}

"La televisión basura es la forma cretina que tiene el medio de
rear programas mediocres que miden tu incultura y tu desgracia
para igualarla, y jamás potenciar lo bueno de esta vida"
Roberto Pettinato
(Humorista, conductor de Radio y TV y periodista argentino)

El término "televisión basura" o "TV basura" viene dando nombre, desde la década de los noventa, a una forma de hacer televisión caracterizada por explotar el morbo, el sensacionalismo y el escándalo como palancas de atracción de la audiencia. La telebasura puede quedar definida por los asuntos que aborda, por los personajes que exhibe y coloca en primer plano y, sobre todo, por el enfoque distorsionado al que recurre para tratar dichos asuntos y personajes (tomado de Manifiesto contra la telebasura en http://www.arrakis. es/ pedra/tvbasura.htm).

Para Gustavo Bueno Martínez, filósofo español, por televisión basura "se designa a cierto tipo de programas que se caracterizan por su mala calidad de forma y contenido, en los que prima la chabacanería, la vulgaridad, el morbo y, a veces, incluso la obscenidad y el carácter pornográfico" (Telebasura y democracia. Cada pueblo tiene la televisión que se merece, 2002).

Bajo una apariencia hipócrita de preocupación y denuncia, los programas de telebasura se regodean con el sufrimiento; con la muestra más sórdida de la condición humana; con la exhibición gratuita de sentimientos y comportamientos íntimos.

Según el Consejo del Audiovisual de Cataluña (CAC) en España, se define la telebasura como el conjunto de programas en los que confluyen "la vulneración de derechos fundamentales, la falta de consideración hacia los valores democráticos o cívicos, como por ejemplo, el desprecio de la dignidad que toda persona merece, el poco o ningún respeto a la vida privada o a la intimidad de las personas o la utilización de un lenguaje chillón, grosero e impúdico. Todo esto se lleva a cabo con la intención de convertir en espectáculo la vida de determinados personajes que, generalmente, se prestan a ser manipulados a cambio de la celebridad que les da la televisión o a cambio 
de contraprestaciones económicas". Por lo tanto la telebasura no es un género televisivo específico (entretenimiento, programas de humor) aunque así lo parezca, sino que puede estar presente en toda la programación televisiva: desde un noticiero a un programa de concursos, desde una telenovela a un magazine.

López Talavera y Bordonado Bermejo en su trabajo sobre Telebasura, Ética y Derecho (2005) señalan que algunos de los argumentos para denunciar un programa como telebasura son la existencia de manipulación informativa, opinión parcializada o tendenciosa, difusión de rumores e informaciones no contrastadas, nulo respeto a la imagen, la intimidad y el honor; conversión del dolor y la miseria humanas en espectáculo recabando en los aspectos más morbosos y sensacionalistas (recordemos nosotros como en un talk show peruano la conductora ofreció dinero a quien lamiera axilas de un sujeto totalmente sudoroso); fomento del escándalo y la violencia; utilización y cosificación del cuerpo humano, en especial el femenino; trivialización de temas sociales controvertidos, el insulto y el griterío en vez del diálogo constructivo; fomento de la pseudociencia y el ocultismo; entre otros, la lista es larga y nos coloca ante la idea que casi todo lo que nos ofrece esa televisión es basura (p. 314).

Para Hugo Landolfi filósofo argentino y Director de la Escuela de Filosofía Aplicada para la Excelencia del Ser Humano en Buenos Aires, "La TV basura es demagógica por definición pues da a las masas de televidentes lo que la mayoría de ellos desean recibir. ¿Desean contenidos sexuales y chabacanos? Se los damos. ¿Desean programas donde no tengan que esforzarse en absoluto? Se los damos. En esto radica esencialmente la ausencia completa de valor que posee este tipo de televisión que busca captar audiencia masivas (para engrosar los bolsillos de los empresarios televisivos a través de la venta de publicidad en esos espacios) realizando constantes estrategias de demagogia televisiva generando contenidos de nulo valor para seres humanos que se precien de ser tales"..."La TV basura, demagógica y manipuladora por naturaleza, explota miserablemente esta natural predisposición a no esforzarse de las personas que están en camino de transformarse en seres auténticamente humanos y les arroja en un pozo sin luz del cual les puede ser muy difícil salir".

Este tipo de televisión de contenidos superficiales, manipuladores, embrutecedores, chabacanos y violentos es a lo que nos referiremos con TV basura. Muchos temas son tratados con la superficialidad propia de quien únicamente busca el espectáculo lucrativo, generando actitudes y representaciones negativas en aquél sector de la audiencia que tiene en la televisión a su única -y más creíble- fuente de información y -quizá- de educación.

En un reciente trabajo realizado por el Consejo Consultivo de Radio y Televisión del Perú, las cifras indican que los peruanos ven en promedio seis horas diarias de televisión y que la mitad de ellos está de acuerdo con los contenidos de la televisión peruana (Concortv, Lima, 2011). Asimismo se concluye que "el equipo con mayor presencia en los hogares peruanos es el televisor (99\%), incluso por encima de la cocina (97\%)". Con datos como estos el panorama es, según nuestro análisis, peligroso.

Hoy podemos afirmar, luego de investigaciones que se irán mencionado en este trabajo que los medios de comunicación (algunos los llamamos también de incomunicación) tienen diversos y variados efectos en las diferentes fases de la vida de una persona.

\section{NUEVOS MODELOS, NUEVOS VALORES}

La televisión (TV) constituye una fuente efectiva en la creación y formación de actitudes en los niños, ya que desde temprana edad, son sometidos a su influencia. Sabemos que los niños seleccionan los programas que divierten más que los que educan. A pesar de que se transmiten programas educativos, pocos niños los prefieren sobre un programa divertido. $\mathrm{Y}$ esa es una constante que se mantendrá en el adulto (Sartori, 2004).

La demanda por el consumo de televisión no es un fenómeno reciente. Una gran cantidad del tiempo que los niños invierten en ver la TV lo dedican a programas concebidos para los adultos (Schramm, 1961). Este dato es confirmado en diferentes realidades educacionales y socioeconómicas donde se puede aseverar que los 
niños pasan más tiempo frente a la TV que en la escuela.

\section{LA VIOLENCIA ESTIMULADA}

En promedio, hay seis veces más violencia durante una hora de "TV infantil" que en una hora de programación de "TV para adultos" nos dice Michael Rothemberg en su clásico trabajo "Efectos of TV violence on children and youth" de hace unas décadas (Rothemberg, 1975).

El psicólogo noruego Ivar Lovaas, considerado uno de los padres de la terapia del autismo luego de estudiar el efecto de comics agresivos y juguetes agresivos concluye que el ver programas con cierta dosis de agresividad estimula en cierto grado los impulsos agresivos de los niños. Algo parecido a los trabajos de Paul Mussen y Eldred Rutherford sobre la lectura de tiras cómicas de animales agresivos y juegos destructivos. Schramm (1961) nos recuerda los trabajos de estos autores mencionados. Ivar Lóvaas, se propuso descubrir si las tiras cómicas que incluían peleas como tema principal, provocaban que los niños mostraran más o menos agresividad después de ver la historieta. Presentó un programa agresivo ante un grupo de niños, y material no agresivo a otro grupo. Inmediatamente después de ver la historieta se pidió a cada niño que eligiera entre dos juguetes para enfrentarse; uno de ellos era un juguete agresivo: si el niño accionaba una palanca hacía que dos muñecos se golpearan en la cabeza. El otro juguete que podía elegir, estaba constituido por muñecos en movimiento, que no se golpeaban. Los niños que habían seguido la historieta cómica agresiva, inmediatamente mostraron inclinación por el juguete agresivo, mientras que los niños que vieron la historieta no agresiva se inclinaron por el juguete no agresivo. Este descubrimiento sugiere que el ver programas con cierta dosis de agresividad estimula en cierto grado los impulsos agresivos de los niños.

Un resultado semejante fue obtenido por Albert Bandura $(1963,1977)$ y colaboradores. Durante la investigación presentaron a un grupo de niños una película en que un adulto golpeaba y daba puntapiés a un muñeco hecho de un balón, con pesas en los pies, el cual también puede utilizarse para practicar boxeo; un grupo control de niños no vio esta película. En una ocasión subsiguiente, cuando había sucedido algo que provocó que los niños se sintieran irritados y frustrados, éstos fueron conducidos, individualmente, a una habitación en la que había un muñeco como el que antes se describió, además de otros juguetes. Los niños qué habían visto la película imitaban con extraordinaria exactitud la conducta que habían presenciado en ella; golpearon y patearon al muñeco, mientras que los niños que no habían visto la película no lo hicieron. En efecto, los niños que no habían visto la película mostraron un menor grado de agresión de todos los tipos en la situación de prueba. Bandura llamó al fenómeno aprendizaje por la observación o modelado, y su teoría usualmente se conoce como la teoría social del aprendizaje. "La observación es el medio más importante en el proceso de aprendizaje y de transmisión de valores y patrones de comportamientos y de pensamiento" (Bandura, 1977).

Un tercer estudio, realizado por Paul Mussen y Eldred Rutherford citados por Schramm (1961), indicó que los niños que acababan de leer una tira cómica de animales agresivos se mostraron más propensos a desarrollar un juego destructivo, que implicaba reventar balones, si se comparaban con niños que no habían leído las historietas.

Scharamm nos recuerda que hay que tener presente que los estudios no demuestran que ver programas agresivos sea la única razón por la cual los niños se vuelvan directamente agresivos con otras personas. En cada caso, la prueba consistió en observar si el niño se volvía más agresivo hacia un muñeco, lo cual es muy distinto de, por ejemplo, golpear a otro niño. No obstante, estos estudios sí apuntan ciertas cosas: en primer lugar, la observación de episodios agresivos en la televisión sirve para estimular sentimientos agresivos en el espectador. Si se produce un decremento en la sensibilidad emocional ante la misma violencia, se nota una mayor agresividad en sus juegos. Finalmente, se asocia a la violencia como recurso o herramienta útil para solucionar conflictos o necesidades.

Los medios educan en una identificación con imágenes basadas en la violencia, la ruptura de normas sociales y la predisposición de conductas basadas en el delito. Ojo, son conocidos los reportes que coinciden en que esto va en aumento y a ritmo acelerado. 
Para Portocarrero (1998) la TV incrementa el potencial agresivo, al reducir las inhibiciones y crea un contexto favorable a las acciones violentistas de los jóvenes.

En el vecino país de Argentina, una encuesta del Centro de Estudios de la Opinión Pública (CEOP), indica que el entretenimiento principal del $77 \%$ de los argentinos es mirar televisión, y casi el $84 \%$ le destina a dicha actividad más de dos horas diarias. De los 2.926.089 niños de entre 5 y 14 años residentes en Capital Federal y Gran Buenos Aires, un 40\% mira de 3 a 5 horas por día. Acerca del impacto de la violencia televisiva en el universo infantil, las Universidades de Quilmes, Buenos Aires y Belgrano, en un trabajo conjunto, descubrieron que en 242 horas de programación se reconocieron 4703 escenas de violencia. Según esta estadística, cada tres minutos se producen imágenes de agresión que se duplican los fines de semana y en períodos de vacaciones. Los autores concluyen que, a lo largo de seis años, un menor acumula en su memoria un total de 85.410 escenas violentas. (Kucharky, L. y Savignano, B., 2005).

\section{LA TV, EL FENÓMENO VISUAL Y UN PODER MEDIÁTICO}

Algunas características de la televisión muy bien analizadas por Giovanni Sartori son:

- Se suele creer en lo que se transmite.

- El tipo de comunicación es unidireccional.

- La información que llega tiene que ver con los valores, normas y actitudes de quienes la transmiten.

Para Carmen Pérez León y colaboradores (1998) en su investigación ¿Por qué los niños ven televisión? Determinación de hábitos televisivos en niños de 6 a 8 años en Caracas: La Televisión presenta estímulos audiovisuales, los cuales son más efectivos que los visuales y auditivos por sí solos. Se impone sobre los otros medios de comunicación por penetrar en el hogar, en la vida diaria y llegar a formar parte del cúmulo de hábitos de cualquier hombre de nuestra época.

Concluyen que los niños recurren a la TV para satisfacer sus necesidades de distracción, reducir las tensiones y como medio para obtener información. Además de las motivaciones personales, podríamos agregar un factor situacional externo al niño: "el niño ve Televisión porque le es impuesta por el medio", la ve porque no le queda otro remedio. Le es ofrecida en el ambiente del hogar y los padres y demás adultos le refuerzan la conducta contemplativa. En muchos casos constituye la única compañía del niño y a veces se convierte en una especie de niñera. El ver TV es un hábito que se refuerza diariamente a través de gestos, sonrisas y aprobaciones verbales de los adultos. (Pérez León, 1998)

Joseph Klapper (1960) luego de investigar los efectos de la comunicación de masas afirma que los niños con tendencias agresivas presentan más tendencia que los niños menos agresivos, a imitar la conducta violenta que observan en las películas y en la televisión.

Investigaciones clásicas de Himmelweit (1958) determinaron que las jóvenes que ven muchos programas de la vida adulta -las podríamos llamar ahora telenovelas- se inquietan por lo que será el matrimonio y consideran la vida adulta una etapa en continua crisis. En cambio las que no ven se muestran más optimistas, alegres, esperanzadas en las recompensas que ofrece ser adulto. Las telenovelas reflejan la sensibilidad melodramática popular y reproducen temas universales como el triunfo de la humilde (e ignorante, dependiente, supersticiosa) cenicienta, con la que muchas seguramente se identificarán. La telenovela actual manipula sueños populares y es irreal (Ponce Alberti, 2001).

Los niños y las niñas españoles de entre 8 y 13 años pasan más de tres horas diarias frente al TV. según la Asociación para la Investigación de Medios de Comunicación de España (2004). Dedican más tiempo a la TV que a la lectura o a cualquier otra actividad de ocio. Para la mayoría de los adultos ver la TV también es la actividad a la que se dedica más tiempo de ocio.

Recordemos lo que dice el filósofo y lingüista estadounidense Noam Chomsky sobre los medios y la búsqueda de la manipulación. La cita es algo extensa pero de esencial lectura: 
"La estrategia de la distracción. El elemento primordial del control social es la estrategia de la distracción que consiste en desviar la atención del público de los problemas importantes y de los cambios decididos por las élites políticas y económicas, mediante la técnica del diluvio o inundación de continuas distracciones y de informaciones insignificantes. La estrategia de la distracción es igualmente indispensable para impedir al público interesarse por los conocimientos esenciales, en el área de la ciencia, la economía, la psicología, la neurobiología y la cibernética. "Mantener la Atención del público distraído, lejos de los verdaderos problemas sociales, cautivada por temas sin importancia real. Mantener al público ocupado, ocupado, ocupado, sin ningún tiempo para pensar; de vuelta a granja como los otros animales...". Dirigirse al público como criaturas de poca edad. La mayoría de la publicidad dirigida al gran público utiliza discurso, argumentos, personajes y entonación particularmente infantiles, muchas veces próximos a la debilidad, como si el espectador fuese una criatura de poca edad o un deficiente mental. Cuanto más se intente buscar engañar al espectador, más se tiende a adoptar un tono infantilizante. ¿Por qué? "Si uno se dirige a una persona como si ella tuviese la edad de 12 años o menos, entonces, en razón de la sugestionabilidad, ella tenderá, con cierta probabilidad, a una respuesta o reacción también desprovista de un sentido crítico como la de una persona de 12 años o menos de edad"... (Chomsky, N., 2012)

Finalmente, pero relacionado al caso mediático Chomsky nos recuerda que una forma de manipular al espectador y consumidor moderno es "estimular al público a ser complaciente con la mediocridad. Promover al público a creer que es moda el hecho de ser estúpido, vulgar e inculto..." (Chomsky, N., 2012)

\section{LOS CONTENIDOS DE LA TV: IMAGEN DE HOMBRES Y MUJERES EN LA PANTALLA}

“La televisión latinoamericana representa la expresión
misógina más abierta, machista y reforzadora de
los tradicionales estereotipos sexuales con sus
correspondientes conductas sadomasoquistas"
Fabiana Porracín, Psicóloga y Antropóloga (UBA)

Tendríamos que hacer un listado de los temas que de manera directa o indirecta se ven influenciados, trastocados y deformados por los contenidos televisivos y sus formas de exposición. Por ejemplo:

- Los roles masculinos y femeninos desfigurados.

- Los estereotipos sexistas.

- Los modelos de belleza femenina.

- La mujer como objeto sexual.

- La ridiculización del homosexual.

- La neurotización de las relaciones de pareja expuestas en las telenovelas. Llamo yo a eso la teleneurosis. (Arboccó de los Heros, 2009).

- El reinado de la chatura y lo cotidiano.

- La vulgarización de la vida, la destrucción del lenguaje y el empobrecimiento temático y cultural.

- La desinformación y manipulación de los contenidos políticos (los ya conocidos trabajos psicosociales de los gobernantes de turno).

Los medios de comunicación ejercen un poder mayor que antes por el "aflojamiento" de las estructuras familiares, ocupacionales y educativas.

La televisión, y ahora la internet, se apropian del poco tiempo del que disponen los niños para dedicarse a las actividades lúdicas y recreativas. Los medios de comunicación se han transformado en el centro fundamental de socialización para la juventud pobre, proceso basado en consumismo y violencia (García y Ramos, 1988). Las cadenas televisivas han producido ciudadanos que muy poco saben y que se interesan por banalidades.

Mejía Navarrete (2005) en su investigación sobre Medios de comunicación y violencia, nos dice: "En un contexto de pobreza y exclusión los medios 
de comunicación crean las condiciones para que los jóvenes marginales reaccionen con furia cuando se ofrece un mundo extremadamente desigual, al que no pueden acceder las mayorías y sólo está vetado para otros sectores minoritarios".

Mónica María Avalos (2009) en su investigación sobre la influencia del consumo televisivo sobre la formación de la identidad de género en niños en Colombia concluye que la televisión "es y seguirá siendo una fuente potencial de reproducción de diferentes modelos a seguir por los niños y niñas, los cuales tendrán un impacto posible en lo que ellos piensan, hacen y en como asumen su identidad de género o cualquier tipo de identidad", también afirma que la televisión "por sí sola no hace todo el papal negativo, sino que esto obedece a la poca orientación de las familias frente a lo que los niños y niñas ven, dando cuenta del poco tiempo que les dedican".

\section{EL TEMA DE LA VIOLENCIA ES RECURRENTE}

La mala televisión o el mal empleo de la televisión, ya lo vemos, exacerba nuestras tendencias más egoístas y destructivas. El tema de la violencia es recurrente. Observemos cómo:

- Como forma de solución de problemas (al final se muestra que con la violencia uno consigue salirse con la suya).

- Violencia vs.Argumento.Se priorizalaverborrea insustancial y la exaltación emocional más que la secuencia lógica y el debate coherente.

- El espectáculo del grito vs. La función de la palabra. Muchos de los tristemente llamados talk shows se convirtieron a vista de paciencia de todos en rings de box, incluyendo patadones, arañazos y jalones de mechas.

- La violencia asolapada, a través de estereotipos, bromas de mal gusto, las influencias casi subliminales, entre otras formas.

- La violencia se transforma en una compañera habitual, en una forma normal de vida. Se incorpora a la casa, a la mesa y al dormitorio. En muchos casos se muestra la violencia como único método de solución.
Si pensamos que es solo un problema de países económicamente pobres, nos equivocamos por ejemplo, un niño en Estados Unidos ve una media de cien mil actos violentos antes de acabar la escuela primaria (Fuente: Centro Cultural Idealia, La Televisión como herramienta de sometimiento, Esmeralda Merino).

Los niños también pueden aprender a creer que las conductas agresivas son una solución aceptable a la provocación, ya que en los programas violentos estas conductas son vistas como moralmente justificables y perfectamente funcionales.

Para Gadow y Sprafkin (1989) "el hecho de ver en la pantalla de TV conductas agresivas, inducirá una conducta similar en los niños los que la aprenderán por imitación".

Ya hemos visto como los trabajos de Albert Bandura concluyen afirmando que los niños pueden aprender conductas agresivas a través de la observación de modelos simbólicos presentados por la pantalla de TV.

Drabman y Thomas, plantean además que los niños que ven con frecuencia programas de TV de contenido violento, se convierten en apáticos a la violencia de la vida real (en Psicología mejor conocido como desensibilización sistemática).

Autores como Gerbner y Gross, citados por Gadow y Sprafkin (1989) en un artículo titulado La Violencia Prolifera, demostraron que durante el año 1989 ocurrió violencia en el $73 \%$ del total de programación de los Estados Unidos y en casi todas las caricaturas infantiles. Para ello usaron como medidas factores tales como: el porcentaje de programas de contenido violento, el número de episodios violentos por programas y el porcentaje de personajes principales implicados en actos de violencia.

Por último, Vicente Romano en su trabajo "La formación de la mentalidad sumisa" (2008) nos indica en su capítulo sobre la violencia: "A finales de los años se calculó que un adolescente español tenía tras sí 15,000 horas de TV con 18,000 muertes ocurridas en la pantalla". Señala a continuación un estudio reciente de la Asociación de Telespectadores y Radioyentes 
donde los niños españoles en edad escolar ven en la televisión cada semana 670 homicidios, 15 secuestros, 848 peleas, 420 tiroteos, 11 robos, 8 suicidios, 32 casos de captura de rehenes, entre otros casos donde la violencia impera y nos plantea un ejercicio matemático si multiplicáramos éstas cifras por las 52 semanas del año (p.117). Nos preguntamos si estas cifras difieren mucho de realidades como la peruana. Creemos que no.

\section{EL HOMO VIDENS DE SARTORI}

En su texto Homo videns: la sociedad teledirigida (2004), el politicólogo italiano Giovanni Sartori analiza el peligro de exponer a los niños -el los llama los videoniños- ante la televisión basura y nos deja una serie de afirmaciones y estadísticas que bien puede ser tomadas en cuenta en muchas realidades sociales, las mismas que están debidamente planteadas y fundamentadas en la obra mencionada. Por ejemplo indica:

- El niño ensimismado con la TV no lee.

- La TV modifica radicalmente y empobrece el aparato cognoscitivo del homo sapiens.

- 95\% de niños entre 3 y 10 años (Italia) ven TV casi todos los días.

- En los EEUU: 3 horas diarias de TV en niños de inicial.

- En los EEUU: 5 horas diarias de TV en niños entre 6 y 12 años.

- El niño formado en la imagen se reduce a ser un hombre que no lee.

- Ese adulto sólo responderá a estímulos audiovisuales.

- El acto de ver está atrofiando la capacidad de entender.

- La reflexión requiere tiempo y reposo.

- El hombre que lee está decayendo rápidamente.

- Lo peor de todo es que (en este mundo actual pareciera que) "ya no se necesita leer".

Estudios señalan que un joven antes de terminar su adolescencia habrá observado por TV más de 13,000 muertes (E. Otero y R. López; 1984). Ese niño luego se transforma en un adulto empobrecido, que no lee, que responde a estímulos casi exclusivamente audiovisuales.
Actualmente, son pocos los niños y adolescentes que leen libros, ensayos o artículos largos que ayudan a concentrarnos y ser introspectivos y contemplativos. La lectura, cuando la hay, se ha reducido a ser rápida, ligera, y de poca exigencia. Como ha mencionado con acierto el estudioso peruano Marco Aurelio Denegri hoy se nos hace cada vez más difícil la introspección, la atención, el esfuerzo, el autoanálisis, la serenidad y la sana búsqueda de la necesaria soledad.

De esta forma vemos cómo los medios de comunicación aportan a la construcción (y destrucción) de modos de ser, de modelos de comportamientos individuales y colectivos. Nos animamos a afirmar que así se van formando modelos pobres, incultos y dependientes de las sensaciones (imágenes, sonidos) descuidando los estímulos ligados al pensamiento (la razón y la lógica) y los pensamientos).

\section{EL ACOSO DE LA TV}

¿Cómo nos puede acosar la televisión con sus contenidos? La respuesta, pensamos, está en la relación directa con las siguientes temáticas de trabajo:

- Manipulación y falsedad en los contenidos noticiosos.

- El reinado de la cotidianeidad. Historias cotidianas, nada especiales las cuáles son presentadas como tremendas historias de vida.

- El desprecio por derechos fundamentales como el honor, el respeto, la veracidad o la presunción de inocencia. Existe un asolapado desprecio por el otro. Una cosa es la broma y otra la burla.

- Vulgaridad. Humor grosero y recurriendo de forma permanente al golpe, la palabrota, el griterío.

- Difamación (las famosas noticias "sin confirmar")

- Temor y más inseguridad. El miedo como alimento diario.

- Consumismo permanente. Comprar para ser.

- Pensamiento ilógico y supersticioso. Suelen tocarse de la manera más infantil, mágica y animista temas que ya son explicados científicamente. El despliegue de mensajes esotéricos y de discursos paranormales, presentados de forma acrítica y en el mismo plano de realidad que los argumentos científicos. 
- La exposición de temas interesantes y serios abordados por inexpertos y charlatanes.

- Pérdida de lo privado. Lo que ahora algunos llaman extimidad, en oposición a la intimidad. El desprecio por la intimidad.

- La intimidad como espectáculo (Paula Sibilia, 2008). Claro ejemplo de esto son los "talkshows" y "reality shows" que aparecen y se multiplican desde la década de los noventa.

- La excesiva puesta en escena de historias superfluas y decadentes que son presentadas como grandes noticias, ejemplo: músicos chicheros que engañan y pegan a sus parejas, futbolistas "ampayados" (1) en estado de ebriedad, infidelidades dentro del mundo del espectáculo, "informes periodísticos" del tipo: ¿existen los extraterrestres?, ¿cómo actúa un macho que se respeta?, ¿crees que se viene el fin del mundo?, ¿qué le pedirías a los reyes magos? entre otros. Hoy el modelo reconocido no es el sujeto más inteligente, el más solidario o el más estudioso, es el más gracioso, la de mejor trasero, el más matón o la que tiene más dinero. Inclusive el que fue más listo en robar. Recuerden aquellos titulares de la prensa sensacionalista sobre la captura del "choro monse" (2).

Entre los mecanismos psicológicos de imitación, la indirecta agudización de ciertos temas cuando son tratados de forma superficial y sin asesoría profesional, la asociación de ciertos estímulos, ejemplo violencia respuesta (conducta) ante la TV están: la identificación con ciertos personajes, la cotidianidad, mujer-objeto sexual, felicidad-consumismo, homosexualidadenfermedad, amor de pareja-sufrimiento necesario, entre otros; también la desensibilización ante el dolor ajeno y la vulgaridad así como un patrón de comportamiento violento y ansioso. La enorme influencia social de la TV y otros medios multiplica de forma exponencial los efectos negativos de este tipo de mensajes.

\section{LA ESTUPIDIZACIÓN DEL TELEVIDENTE}

"La televisión peruana ha creado una muchedumbre analfabeta, adicta a lo más barato con programas salidos del estercolero"

César Hildebrandt

No es solo la violencia el tema ligado a la TV lo que nos preocupa. Con cierta frecuencia escuchamos de personas cultas que ya peinan canas, todos ellos asombrados, como los contenidos de la TV actual (la peruana y las de otros países) son cada vez más simplones, improvisados, baratos en calidad y sustancia, alejados de la información precisa, científica y humanista, distanciados del lenguaje correcto y bien empleado, de la facilidad con que a cualquier hijo de vecino se le permite salir y mostrarse en pantalla. La mayoría de las veces sin mérito alguno, y solo por haberse peleado con alguien o aparecer en un escándalo cualquiera o haber sido infiel o haber sufrido un "ampay" saliendo de algún lugar o (en caso de las mujeres) tener un cuerpo mostrable, entiéndase enorme tetamenta y un trasero agigantado por las siliconas. Nunca como hoy cualquier improvisado(a) y casi mononeuronal individuo tiene opción de ser visto a lo largo del territorio nacional pudiendo -como ya hemos demostrado- ser tomados en cuenta por los espectadores, sobre todo los siempre más vulnerables: niños sin asesoría, adolescentes extraviados y lentos cognitivamente y adultos, en su mayoría, con un pensamiento operacionalmente concreto para hablar en términos piagetianos. Pero recordemos que hablamos de los que conforman la gran parte de los teleconsumidores, son los nuevos televidentes de la post modernidad.

Si la TV peruana va a tener como protagonistas, ya no a los profesionales del caso: periodistas, comunicadores, sociólogos, además de señores actores (hoy por hoy se le llama actor o actriz a cualquier improvisado) sino a personas como las que vemos: actores por autodenominación, vedettes, "chicheritos", periodistas contratados para hacer campañas pro

1. Ampayar: En el Perú significa sorprender a alguien, descubrirlo (DRAE)

2. En marzo del 2010 fue detenido en Lima un trabajador de una empresa de transportes blindados (Hermes) que había fugado con dos millones de soles. Capturado a las pocas horas del robo fue bautizado por la prensa como el "choro monse" (en el Perú se llama choro al ratero y monse al aburrido, al tonto). 
partidos políticos en época electoral, cómicos ambulantes de plazuelas, contadoras de chismes y calumnias, entonces la situación mediática nacional es de pronóstico más que reservado, en el mejor de los casos. Y todo esto avalado y fervientemente esperado por una masa desinformada, simplona y de mentalidad cuasi infantil.

Hoy por hoy futbolistas opinan de arte y conducen programas de $\mathrm{TV}$, los políticos más mediocres y trepadores opinan de ética y son jurados en concursos de baile, los maquilladores y cosmetólogos opinan de filosofía e historia, y los conductores de magazine, sin reserva alguna, dan conferencias sobre relaciones de pareja y la personalidad infantil, y así se cierra un círculo vicioso, muy nocivo para la sociedad, donde ya nadie ocupa el rol social que le compete en relación a sus capacidades y esfuerzos (meritocracia).

Los que esto escribimos, como psicólogos, sentimos preocupación cuando no indignación al ver aparecer sujetos con estudios básicos que se sienten la panacea y los enviados de la razón, aquellos que creen que lo que dicen es ley en materia psicológica y social. La televisión, ausente del debido control de calidad, presta su espacio para muchos individuos que subliman sus anhelos de fama y creen que porque leyeron un par de textos o se graduaron a patadas de algún cuestionado centro de estudios, pueden salir a decir cualquier cosa -generalmente frases hechas, lugares comunes- que les permitan sus anchas agallas. Habría que preguntarse cuántos de ellos gozan del reconocimiento y del prestigio en sus respectivas sociedades, asociaciones y colegios profesionales.

Y esto sucede en muchas partes, por ejemplo Kucharky, L. y Savignano, B. (2005) señalan: “... Pero cuando las opiniones se refieren a cuestiones donde es imperante que hagan uso de la palabra aquellos quienes han sacrificado una vida al estudio, no han de ser tomadas con una seriedad inobjetable aquellas opiniones de personas que no son doctas en dichos temas, tal como se hace hoy en día. Pareciese que la opinión del hombre común, no solo vale más, sino que neutraliza y reduce aquellas de personas con más capacidad técnicas e intelectuales".

Algunos levantarán la mano y reclamarán la tan manoseada libertad de opinión (como aquél gracioso slogan de una radio local que pregona "tú opinión importa") dejando de lado el hecho de que si bien todos tenemos opiniones, pues no toda opinión es válida, coherente, lógica y fundamentada. Sobre todo cuando hablamos de temas importantes. Es decir, vivimos en el mundo donde toda opinión -en especial las ociosastiene un espacio. Y eso, sabemos los académicos, es falso y peligroso.

\section{COMENTARIOS SOBRE LA TV PERUANA ACTUAL}

A continuación presentamos algunos breves pero contundentes comentarios sobre la televisión peruana de los últimos años pertenecientes a gente de las ciencias, el arte y el propio mundo de la televisión (los numerados son tomados del trabajo de Ponce Alberti, 2001).

1. "Invade la vida cotidiana, ocupa el espacio de la lectura y de la conversación amical" (Alejandro Ortiz, sociólogo)

2. "No requiere concentración" (Hernando Cortéz, director y actor teatral)

3. "Es un instrumento que se puede usar bien o mal, está mal en el Perú porque nuestro nivel cultural es muy bajo"(Emilio Barrantes, educador)

4. "Por ser comercial, gratifica las malas costumbres de lo sectores no educados, refuerza los mecanismos de ineducación" (Leopoldo Chiappo, psicólogo)

5. "Se hace mal uso de ella porque está en manos de comerciantes a quienes interesa hacer dinero presentando lo que consideran gusta a la mayoría" (Emilio Barrantes, educador)

6. "Es una cajita idiota, la mayoría de sus programas carecen de nivel cultural y tienen vulgaridad y violencia" (Tomás Escajadillo, ex decano de la facultad de Letras de la UNMSM)

7. "La gran masa se satisface con programas escandalosos sin contenido político o educativo ni problemática social o humana" (Luis Rey de Castro, periodista).

8. "La mujer sigue siendo un objeto de consumo" (Víctor Delfín, artista plástico) 
9. "La tv considera que hay que presentar la basura en forma constante y permanente. Esto puede llevar al espectador a concluir que la realidad es basura" (Armando Robles Godoy, cineasta y escritor)

Según Humberto Ponce (2001) en su trabajo sobre la televisión peruana nos dice: "La televisión no educa, no presenta opciones suficientes de programas positivos, no vertebra el espacio público de comunicación actual que se basa en la imagen. $\mathrm{Su}$ carácter comercial la lleva a contenidos de baja calidad y a resaltar lo negativo, afectando los valores". (p.125)

Para el conductor de programas de difusión cultural Marco Aurelio Denegri (2010) los dueños de los canales (de TV) nunca se van a autorregular mientras tengan éxito comercial. Ellos se amparan en que uno puede hacer todo aquello que la ley no prohíbe. No hay ninguna ley en contra de esparcir basura. Además es tajante al decir..."Responsable, no única, pero sí principalísima de esta bestialidad, de este embrutecimiento, es la televisión comercial. La persona bruta, o la que ha sido embrutecida por la televisión, no puede desarrollarse ni progresar". (Revista Domingo, La República, 10 de octubre 2004)

En la programación televisiva peruana actual podemos considerar TV basura a los conocidos programas prime-time (horarios de máxima audiencia) donde la temática son los chismes, la simple vida farandulera, historias devecindades con vidas cotidianas tomadas como grandes obras artísticas, programas de concursos cuando no de escándalos, además de los famosos programas por la mañana y de mediodía con su trillada y repetitiva propuesta sexista - para amas de casa- sin olvidar mencionar muchas telenovelas con sus triángulos dramáticos de villanos, víctimas y salvadores y sus mágicas propuestas de resoluciones $\mathrm{y}$ finales felices para todos, luego de grandes dosis de engaños, sufrimientos y maquiavelismo del estilo más neurótico posible; cabe mencionar finalmente esos espacios ocupados por sectas y agrupaciones religiosas (más bien "hipnótico-económicas") además de algunos noticieros que encajan en el diagnóstico mediático realizado en este trabajo (con secuencia de horóscopo incluida). Curiosamente muchos de los programas mencionados son los que más rating alcanzan permanentemente (3) (¿o será también que esas cifras están manipuladas para convencernos de la importancia y calidad del programa en cuestión?). Muchas empresas se suman al circo ofreciendo millonadas de dinero para auspiciar estos espacios. Como veremos más adelante, la responsabilidad de tener en tan mal estado la TV peruana es de todos.

\section{REFLEXIONES FINALES Y FORMAS DE ENCARAR EL PROBLEMA}

"Si entre todos logramos romper el círculo de la violencia, pronto podremos gozar de medios realmente educativos, recreativos y formativos que doten nuevamente de significado a la vida, cuya interacción simbólica favorezca la creación de identidades, sirva al desarrollo de las personas, resuelva necesidades familiares, oriente el actuar social, promueva la libertad, la responsabilidad, la solidaridad, la justicia y la búsqueda de la verdad. En ese momento regresará al hombre la mirada"

Rebeil y Guadalupe

"Solo el libro podrá competir con nuestra empobrecida televisión. Sin libros al alcance de las mayorías, quien seguirá teniendo la palabra de mando es la caja boba (TV). La televisión idiotizante destruye los valores básicos sobre los que se sustenta una sociedad" Guillermo Giacosa

"La lectura es el refugio ante la hostilidad de la sociedad actual" Manuel Arboccó de los Heros

3. Se puede consultar el arrastre popular de la TV basura en direcciones como: http://peru.com/2012/07/20/entretenimiento/espectáculos/sepa-cuales-son-25-programas-mas-vistos-tv-noticia-76237; o http://elcomercio.pe/espectaculos/1402865/noticia-rating-programas-mas-vistos-tv-peruana-dia-lunes; y http://ayaviri.info/2012/05/conozca-los-25-prgramas-mas vistos-de-la-television-peruana/ 
Es por todos conocido que la tarea de la educación es desarrollar integralmente a los individuos, y la educación moral nos obliga a escuchar las propuestas que desde la psicología y otros campos se han levantado. Compartimos con la psicóloga Susana Frisancho (2001) la idea de que la verdadera educación consiste en aportar las condiciones necesarias para permitir a las funciones cognitivas y afectivas madurar y desarrollarse. Y hoy (y ya para siempre) un vehículo de educación también son los medios y la tecnología.

Llegado a este punto es indesligable el desarrollo moral del desarrollo integral de los seres humanos. El papel de la familia y de la escuela, se confirma una vez más, vuelve a ser crucial.

Los psicólogos que investigan el tema moral defienden una educación moral que apunte a desarrollar las más altas capacidades de juicio y discernimiento así como la toma de perspectiva y la empatía, en lugar de una educación que simplemente inculcará en los estudiantes las convenciones de su sociedad. En esta tiranía del rating (la auspiciocracia) se quiere hacer creer que es "normal" y hasta necesario consumir ciertos contenidos, creemos que no podemos dejar de denunciar los trasfondos que encierran esas políticas.

\section{CONCLUSIONES}

1. La influencia de la televisión es amplia pero no es ilimitada, aunque impone al televidente un marco de temas. Los programas masivos afectan el modo de ser de la gente, sobre todo gente sin mucha profundidad. (Ponce, 2001).

2. Está claro que la observación de episodios agresivos en la TV sirve para estimular sentimientos agresivos en el espectador Los niños aprenden mientras presencian los espectáculos y les cuesta diferenciar la realidad de la fantasía. La televisión afecta los valores y modelos de conducta en proporción al tiempo que se le dedica.

3. La violencia, la discriminación, el sexismo, el pensamiento supersticioso y el sentimiento de culpa están muy presentes en muchos de los contenidos actuales de la comunicación masiva peruana e internacional.

4. En los últimos años, el nivel de penetración de la televisión ha crecido tanto, que su impacto y credibilidad representa el mayor porcentaje de aprendizaje social de un individuo.

5. La publicidad televisiva recibida acríticamente instala al público juvenil en la superficialidad vital, el embrutecimiento y la estrechez mental.

6. Los estereotipos sexuales empleados por los anuncios televisivos resultan inadecuados y no fomentan una cultura de la igualdad y la cooperación entre los jóvenes.

7. El uso que se le dé a la TV depende en gran medida de las decisiones que se tomen en la familia.

8. Finalmente, ante este diagnóstico se hace necesario mantener una actitud atenta y crítica ante los contenidos en los programas de TV (también con la prensa escrita y radial e internet) pues no solo se trata de ciertas novelas, películas o series groseras o violentas, también existen ciertos "programas periodísticos", "noticieros", "programas de entretenimiento" que contribuyen a la vacuidad, estupidización y bajura.

9. Los colegios profesionales o instituciones académicas (psicólogos, periodistas, publicistas, médicos, educadores, sociólogos) $\mathrm{y}$ sus colegiados tienen en sus manos la posibilidad de cambiar esta situación. No dejemos de trabajar en esto, el beneficio será global.

\section{RECOMENDACIONES}

Luego de estas reflexiones y compilación de estudios realizados sobre los desastres cognitivos, afectivos y morales que sindican a la televisión, sus malos contenidos y sus pésimas y egoístas direcciones se hace necesario, una vez más, un trabajo 
interdisciplinario y multisectorial que se ve reflejado en estas recomendaciones finales que proponemos a continuación. Algunas demandarán tiempo y solo se conseguirán trabajando cuando no luchando por alcanzarlas, otras son sencillas, cotidianas y fáciles de practicar. El que tenga ojos (y quiera ver) que vea:

1. Alfabetización ética para los medios y una aguda reflexión del tipo de afectación que tiene el mal manejo del lenguaje y la imagen en la TV. Requerir y exigir de los medios un comportamiento ético (código moral en radio, prensa y TV).

2. Las empresas televisivas son responsables de los contenidos que emiten. Los padres de orientar y acompañar a sus hijos cuando ven televisión. Las escuelas lo son de debatir, discutir y orientar a los niños respecto a la TV. Y el gobierno es responsable de fomentar programas especialmente dedicados a incentivar el sentido de realidad del niño y a mejorar su nivel educativo y cultural (Ponce, 2001).

3. Educar a los alumnos, a la familia, a los maestros y miembros de otras instituciones formativas en el mejor empleo de los medios

4. Promover la consciencia crítica de todos los actores sociales (familia, profesores, psicólogos, publicistas, comunicadores, periodistas, administradores, abogados $\mathrm{y}$ jueces). Este es un tema que nos compete a todos.

5. Mejor selección de la programación que se ve. Cuantas más personas vean un programa basura más posibilidades tendrá de perdurar.

6. Seleccionar los programas educativos, informativos y de entretenimiento. Tarea a cargo de los adultos y tutores quienes harán una suerte de, lo llamaremos, "telepedagogía".

7. Rechazo a la programación y propaganda violenta, discriminatoria, dogmática, incoherente y supersticiosa.

8. Educar a los pequeños en un espíritu crítico ante los contenidos mostrados en los medios. No se trata de tragar TV, sino de alimentarse con ella, de ser posible.
9. Mayor participación del psicólogo y los profesionales de las ciencias sociales, analizando y denunciando a los agentes sociales que embrutecen, dañan, restringen el desarrollo humano en todo su potencial.

10. Promover la exposición a la TV como una opción y no como un hábito. Como dice el pensador uruguayo Eduardo Galeano "ojalá llegue el día donde el televisor deje de ser tratado como el miembro más importante de la familia y sea tratado como la plancha o el lavarropas". Proponemos realizar otras actividades en vez de sólo distraerse viendo TV: por ejemplo: leer, pintar, practicar algún deporte, pasear, asistir al teatro, estudiar cursos. Recordamos haber escuchado a nuestro Premio Nobel Mario Vargas Llosa denominar a la literatura "un entretenimiento, pero superior". En un hogar donde sus miembros miran televisión durante veinte o treinta horas semanales, ya no queda tiempo para otros pasatiempos o actividades. Además la TV basura empobrece el aparato cognitivo.

11. Discutir con los niños, adolescentes y jóvenes los programas y las películas y orientarlos cada vez que se pueda.

12. Esta recomendación va para los adultos de casa y en especial para los padres: Reducir la cantidad de aparatos de televisión. Hace años los autores de este artículo recordamos como al contar con un televisor en casa esto llevaba a la mirada colectiva (familiar) de una serie o programa, la cuál iba luego acompañada por alguna conversación sobre lo visto. Hoy es fácil encontrar tres, cuatro o cinco aparatos de televisión repartidos en las casas (algunos lo llaman prosperidad) facilitando esto una suerte de separación familiar donde cada uno observa el mismo programa, muchas veces, pero a solas, cual autista encerrado en sus propias contemplaciones. A más televisores puede que estén más separados los miembros de una familia. Lo planteamos para el debate.

13. No nos dejemos llevar por el supuesto "éxito" de ciertas series que son anunciadas con bombos y platillos como las revelaciones televisivas de la época o las que han revolucionado lo hecho 
en televisión. Conviene recordar que más no siempre es mejor. Además existe toda una parafernalia empresarial para posicionarlas. Basta recordar los avances en noticieros y los titulares de ciertos diarios de la capital que nos "noticiaban" de lo "último" y "lo mejor" de la serie, serie cuya misma empresa produce, y que horas después será proyectada en el canal de su empresa. Así se asumen como "juez y parte" y tienen todo un montaje de sugestión y convencimiento popular.

\section{REFERENCIAS}

Avalos, M. (2009). Influencia del consumo televisivo sobre la formación de la identidad de género en la niñez intermedia (8-12 años). Revista Zona Conductual. Recuperado en marzo de 2012 de http://es.scribd.com/doc/22736020/cia-DelConsumo-Televisivo-Sobre-La-Formacion-deLa-Identidad-de-Genero-en-La-Niñez-InterMedia.

Arboccó de los Heros, M. (2009). Efectos de los medios de Comunicación en las representaciones sociales de niños y adolescentes. Ponencia presentada al VI Congreso Nacional de Investigación de Estudiantes y Profesionales de Psicología. UIGV: Lima

Bandura, A. (1963). Aprendizaje Social y Desarrollo de la Personalidad. Madrid: Editorial Alianza.

Bandura, A. (1977). Social Learning Theory. General Learning Press.EUA.

Bueno Martínez, G. (2003). Telebasura y democracia. Cada pueblo tiene la televisión que se merece. Madrid: Ediciones Punto de Lectura.

Consejo Consultivo de Radio y Televisión, Concortv. (2011). Estudio de actitudes, hábitos y opinión sobre la radio y televisión en el Perú. Tomado de http://www.concortv.gob.pe/index.php/ biblioteca-digital/estudios/846-2011-estudio-deactitudes-habitos-y-opinion-sobre-la-radio-ytelevision.html (Recuperado en enero 2012):
Chomsky, N. (2012). Manipulación mediática. Tomado de: http://www.facebook.com/permalink. php?story_fbid $=223780137725527 \&$ id $=1703106$ 03072481 (Recuperado el 20 de mayo de 2012).

Denegri, M.A (10 de octubre 2004). Lima: Revista Domingo, Diario La República.

Denegri, M.A. (agosto 2010) En entrevista de José Ramírez González para la Revista Gente, LimaPerú. Entrevista recuperada en http://elrafo. lamula.pe/tag/denegri.

Frisancho Hidalgo, S. (2001). Aportes de la Psicología a la comprensión del fenómeno moral. Ponencia presentada en el marco de la Cátedra Andina de Educación en Valores. Lima.

Gadow \& Sprafkin. (1989). Field Experiments of Television Violence with Children Evidence for an Environmental Hazard. Pediatrics, 83 (3).

García, S. y Ramos, L. (1998). Medios de comunicación $y$ violencia. FCE, México.

Hildebrandt, C. (13 de abril de 2003). Lima: Programa televisivo "Entre Líneas", Canal N.

Himmelweit, F., Oppenheim, A. N. y Vince, P. (1958). Television and the Child. Nuffield Foundation, Londres, Nueva York: Oxford University Press.

Klapper,J.(1960). The Effects of Mass Communication. The Free Press: EUA.

Kucharky, L. y Savignano, B. (2005). Televisión basura. Mito o Realidad. Argentina: Facultad de Ciencias Económicas y Empresariales, Universidad de Morón. (Recuperado en http: //www.monografias.com/trabajos25/televisionbasura/television-basura.shtml, junio del 2012).

Landolfi, H. (2007). ¿Es nociva la TV basura para nuestros niños y adolescentes? (Recuperado en http: //www.sabiduria.com/liderazgo/tv-basura/, junio del 2012)

López Talavera, M. y Bordonado Bermejo, J. (2005). Telebasura, Ética y Derecho. Límites a la Información de Sociedad en televisión. España: Universidad Rey Juan Carlos. Disponible en dialnet.unirioja.es/servlet/dcfichero_articulo? codigo $=2539878$ 
Manifiesto contra la telebasura, recuperado en línea desde http: //www.arrakis.es/ pedra/tvbasura. htm, en julio del 2012)

Mejía Navarrete, J. (2005). Medios de comunicación y violencia. Los jóvenes pandilleros de Lima. En Cuaderno Venezolano de Sociología, 14 (3

Otero, E. y López, R. (1984) Televisión y violencia. Santiago: Eds. Cerro Huelén.

Ponce Alberti, H. (2001). Imágenes críticas de la televisión peruana actual. La función social de los medios de comunicación. Lima: Universidad de San Martín de Porres. Escuela Profesional de Ciencias de la Comunicación.

Portocarrero, G. (1988). Razones de sangre. Aproximaciones a la violencia política. Lima: Pontificia Universidad Católica del Perú.

Pérez León, C., Rodríguez Lanza, M. y colaboradores. (1998). ¿Por qué los niños ven televisión? Determinación de hábitos televisivos en niños de 6 a 8 años. Ciudad de Caracas. Recuperado en http://cyberpediatria.com/porquetv.htm
Real Academia Española. (2001). Diccionario de la Lengua Española. Vigésima Segunda Edición. Versión virtual disponible en: http://www.rae.es/ rae.html

Rebeil, M.A. y Guadalupe Gómez, D. (2008). Ética, Violencia y Televisión. México: Edit. Trillas.

Romano, V. (2008). La formación de la mentalidad sumisa. Lima: Educap/Escuela Pedagógica Latinoamericana, EPLA.

Rothemberg, M. (1975). Effects of TV. violence on children and youth. Jamal, 10. 234:1043-1046.

Sartori, G. (2004). Homo videns: la sociedad teledirigida. España: Edit. Taurus.

Sibilia P. (2008). La intimidad como espectáculo. Buenos Aires: Fondo de Cultura Económica.

Schramm W., Lyle, J. y Parker, E. (1961). Television in the lives of our children. Stanford: Stanford University Press. 